\title{
Insights into Protein-Ionic Liquid Interactions Aiming at Macromolecule Delivery Systems
}

\author{
Liliam K. Harada, ${ }^{a}$ Jorge F. B. Pereira,${ }^{b}$ Welida F. Campos, ${ }^{a}$ Erica C. Silva, ${ }^{a}$ \\ Carla G. Moutinho, ${ }^{c}$ Marta M. D. C. Vila, ${ }^{a}$ José M. Oliveira Jr., ${ }^{a}$ José A. Teixeira, ${ }^{d}$ \\ Victor M. Balcão $o^{*, a, d}$ and Matthieu Tubino ${ }^{*, e}$ \\ ${ }^{a}$ Grupo de Pesquisa Intelligent Biosensing and Biomolecule Stabilization $\left(i(b s)^{2}\right)$, \\ Laboratório de Biofilmes e Bacteriófagos (PhageLab), \\ Universidade de Sorocaba, 18023-000 Sorocaba-SP, Brazil \\ ${ }^{b}$ Departamento de Bioprocessos e Biotecnologia, Faculdade de Ciências Farmacêuticas, \\ Universidade Estadual Paulista (Unesp), 14800-901 Araraquara-SP, Brazil \\ ${ }^{c}$ Energy, Environment and Health Research Unit (FP-ENAS), \\ University Fernando Pessoa, 4249-004 Porto, Portugal \\ ${ }^{d}$ Centre of Biological Engineering (CEB), University of Minho, 4710-057 Braga, Portugal \\ eInstituto de Química, Universidade Estadual de Campinas (Unicamp), \\ 13083-0970 Campinas-SP, Brazil
}

\begin{abstract}
Over the last few years, researchers have started to explore a particular class of compounds defined as ionic liquids (ILs) in attempts to use their unique characteristics. Since ILs have a very low vapor pressure, these fascinating compounds hold great potential as high performance chemicals for several applications in the (bio)pharmaceutical industry. In general, and unlike common organic solvents with comparable polarities, ILs are quite compatible with enzymes (enhancing their structural and chemical stability) and other proteins, since they can promote higher selectivities, faster reaction rates and greater enzyme stabilities in biocatalytic reactions providing, at the same time, a path for the structural and functional stabilization of protein entities. ILs appear to enhance the delivery of macromolecules, particularly protein entities, and their interactions with ILs will be tackled in detail in this review paper.
\end{abstract}

Keywords: ionic liquids, structural and functional stabilization, protein stability, biopharmaceutical applications, transdermal drug delivery

\section{Introduction}

Commonly, ionic liquids (ILs) are organic, highly viscous low volatile salts, displaying low melting points (arbitrarily defined as compounds with melting points below $100{ }^{\circ} \mathrm{C}$ ), consisting entirely of charged species (ions) and some being liquid at room temperature..$^{1-5}$ The search for new, different ILs, has progressively led to the development of three generations of ILs. ${ }^{6}$ The first generation was focused mainly on their unique intrinsic physicochemical properties (such as density, viscosity, conductivity, solubility, and high thermal and chemical stabilities). The second generation of ILs made it possible

*e-mail: victor.balcao@prof.uniso.br; tubino@iqm.unicamp.br to tailor some of these physicochemical properties, allowing applications as lubricants, energetic materials (in selective separation and extraction processes), and as "greener" reaction solvents. The third (and most recent) generation of ILs involve active pharmaceutical ingredients (API), which are being used to produce ILs with biological activity. ${ }^{6}$ Additionally, ILs are thermodynamically stable (stable at high temperatures and pressures), and with the development of the third generation of ILs, it was shown that they may be even produced from inexpensive and generally recognized as safe (GRAS) starting materials. ${ }^{7}$ These characteristics in association to interesting solvent properties, ${ }^{1-3,8-13}$ in particular, because ILs are able to dissolve some apolar molecules as well as some very polar ones, make them promising compounds for the pharmaceutical processing. 
In addition to their unique properties, ILs are considered "tailored or designer solvents" because their physicochemical properties (viz. viscosity, density, miscibility with other solvents, melting point) fully depend on their structure and can be adjusted by altering the anion and/or the cation. ${ }^{14}$ The tunable nature of ILs has led to their use in many novel applications, from the material science to the more innovative application in life sciences and medicine. ${ }^{15}$ A large number of studies on the properties and applications of ionic liquids have been performed in the last decades, and interesting discussion reviews have been already published, namely in life sciences, food and health applications, and towards the development of IL-nanosystems. ${ }^{16-26}$

The structure of ILs is totally different from that of any other (classic) solvent made of molecules, whose properties depend upon the interactions between their constituent molecules. If such interactions between the molecules constituting the solvent are strong, the solvent is termed "polar" (e.g. water and alcohols with small alkyl chains). On the other hand, if such interactions are weak, the solvent is termed "apolar" (e.g. hexane, heptane, among others). Hence, one distinctive feature of ILs lies in the fact that they are not made of molecules, but ions. A particular substance is in the liquid state when the interactions between its constituent species (either molecules or ions) are stronger than those existing in the gaseous state, but weaker than those that lead to the solid state. Due to these energetic interactions, the vast majority of liquids is comprised of neutral molecules since the presence of charged species determines the existence of ionic interactions, which are typically strong enough to drive the substance to a solid state of aggregation. ${ }^{1,27,28}$ If one compares a typical IL, e.g. 1-ethyl-3-methylimidazolium ethylsulfate, with a typical inorganic salt, e.g. $\mathrm{NaCl}$, it becomes obvious why there is a difference between them (see Figure 1).

The IL has a significantly lower symmetry. Furthermore, the charge of the cation as well as the charge of the anion is distributed over a larger volume of the molecule via resonance. As a consequence, solidification of the IL will occur at lower temperatures. In some cases, especially if long aliphatic side chains are involved, a glass transition is observed instead of a melting point. The strong ionic (Coulomb) interaction within these substances results in a negligible vapor pressure (unless decomposition occurs), a non-flammable substance, and in a high thermally, mechanically as well as electrochemically stable product. In addition to this very interesting combination of properties, ILs offer other favorable properties such as very appealing solvent properties and, depending on their particular ion composition, miscibility or immiscibility with water and organic solvents that result in biphasic systems. The choice of the cation has a strong impact on the properties of the IL and will often define its stability. The chemistry and functionality of the IL is, in general, controlled by the choice of the anion. ILs are widespread in chemistry, although not generally described as ILs, but known by their features, such as their ability to act as ionic surfactants. ${ }^{29}$ Thus, recently, ILs bearing long alkyl-chains were termed surface-active ionic liquids (SAILs) due to their intrinsic amphiphilic nature (which includes some of charged surfactants that are liquid at low temperatures). The peculiar aggregation behaviors of SAILs have drawn great attention in the field of colloid and interface chemistry. SAILs also have a respectable and important scope in pharmaceutical fields due to their ability to enhance the permeability of drugs across biomembranes and, in this manner, to act as better drug carriers as compared to conventional cationic surfactants, ${ }^{1,30,31}$ in particular because they are liquids, their solubilization power for very hydrophobic substances in water is greatly intensified. ${ }^{29}$

An in-depth analysis of the nature of interactions in ionic substances shows that they have a wide degree of variation, enabling the preparation of fluids exhibiting different ionic character (i.e., ILs). ILs may thus be described as organized three-dimensional networks of anion and cation species, both in the (semi)solid and liquid states, as a result of different strong, but screened short-

(a)
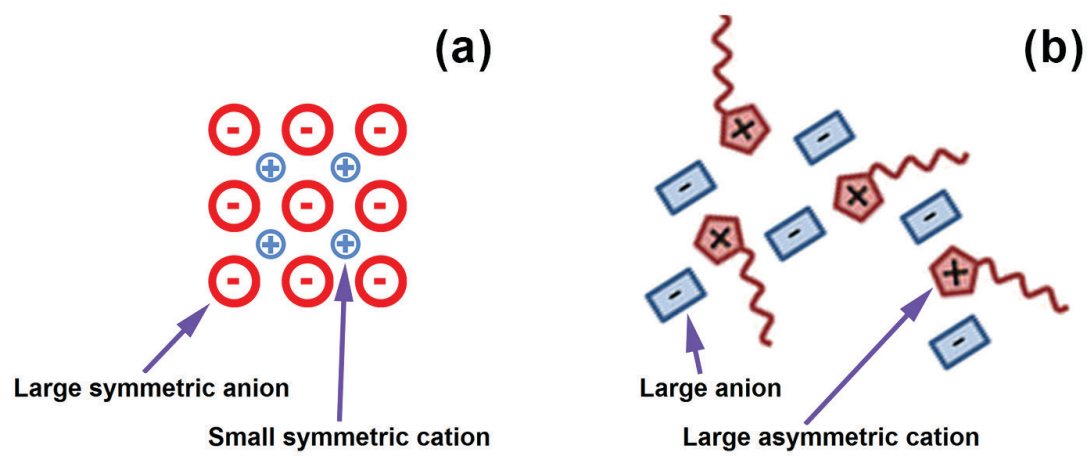

Figure 1. Comparison between a typical inorganic salt (a), e.g. sodium chloride, and a typical ionic liquid (b). 
ranged electrostatic interactions similar to "classical" high-temperature molten salts. Such organized threedimensional network structures are maintained when ILs are dissolved in solvents with moderate to low polarities, a behavior that characterizes such salts as supramolecular structures. ${ }^{1,27,28}$ Different ILs display different properties as a result of all weak interactions present. Hence, although an understanding of such force balance is not trivial, it is of utmost importance for an enlightenment of the nature of ILs and facilitating both the planning and design of new ILs with specific properties. Ionic interactions do play a major role in the understanding of the physicochemical and biological phenomena involved in protein folding/ unfolding and refolding processes. ${ }^{8,32-34}$ The potential applications and advantages of ILs have now been well recognized by the scientific community, in particular due to the dynamic and tunable potential of ionic species in liquid phase. In this context, because ILs display low melting points and are entirely composed of chemically distinct ions, they have been progressively changing the picture of protein/enzyme stability in conventional organic solvents, ${ }^{35,36}$ some of them being now generally considered as more biocompatible alternatives to the volatile organic compounds (VOCs) ${ }^{25,37,38}$ Although some ILs may be less toxic than VOCs, there are ILs (particularly imidazolebased ones) that are more toxic than VOCs..$^{25,37,38}$ Salt ions are classified as being either kosmotropic (structure makers) or chaotropic (structure breakers), according to their relative abilities to induce the (re)structuring of water molecules. Small ions (kosmotropes), due to their high charge densities, promote a strong electrostatic ordering of nearby water molecules by breaking hydrogen bonds between them. In contrast, large ions (chaotropes) possess low charge densities and, therefore, surrounding water molecules are mostly hydrogen-bonded. Protein stability and enzyme activity/stability in aqueous solution can be strongly influenced by the type of salts present therein. ${ }^{34,35,39,40}$ IL-induced stabilization/destabilization phenomena of the protein entity's nanoenvironment are just starting to be tackled..$^{35,41-49}$ In this context, several researchers have reported that a specific combination of a chaotropic cation and a kosmotropic anion possess the ability to stabilize proteins. ${ }^{35,50}$ One of the most interesting feature of ILs to control the stability, selectivity and activity of enzymes, lies in the fact that they can interact both with water and protein surface (see Figure 2), ${ }^{15}$ and thus, they can be used in a wide range of (bio)applications, such as: protein aggregation and solubilization; crystallization; enzymes enhancers or stabilizers; ${ }^{52}$ in the control of protein reversible folding/ unfolding; activation and denaturation. ${ }^{51}$

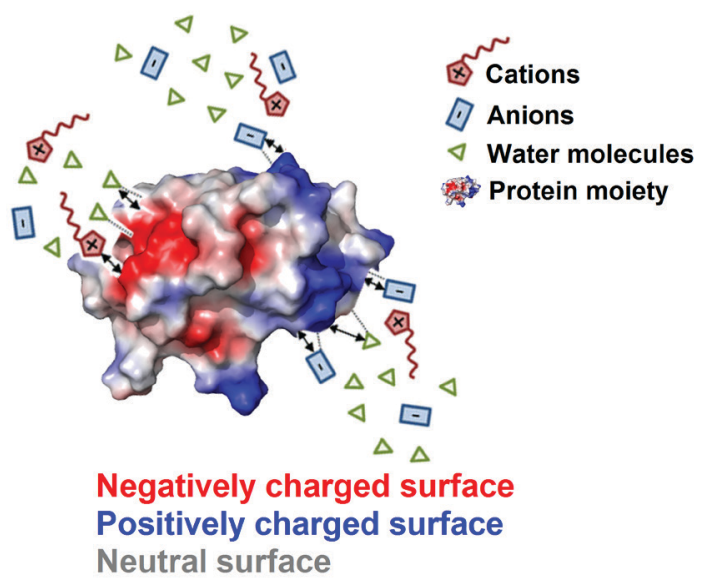

Figure 2. Putative interactions (dotted lines representing hydrogen bonding and arrows representing strong Coulomb interactions) between solvent species with a protein surface, at high ion concentrations (adapted from reference 51).

Recently, both ILs and deep eutectic solvents (DES, a mixture of charged and neutral species, either in equimolar or imbalanced ratios that, when combined, have a much lower melting point than the individual components) were found to increase drug solubility, improving drug formulations, specially, applied as carriers for topical drug delivery. ${ }^{35,53-61}$

\section{Relevant Physicochemical Properties of ILs}

As recently demonstrated, ${ }^{62}$ the properties of ILs at molecular level allows a modulation of different levels of organization (nanoscale and microscale). Due to this ordering and organization (not observed in common molecular liquids), ILs exhibit unique physicochemical characteristics, including (but not limited to) quite low melting points, negligible vapor pressures and high electric conductivity, ${ }^{1,16,59,63}$ which have attracted more and more attention for numerous applications. ${ }^{15}$ Due to the wide range of potential applications of ILs, below some important physicochemical characteristics are reviewed, in particular because ILs have the capability to exert positive effects on the stability, solubility and activity of biomacromolecules such as protein entities. Enzymes, for example, remain trapped in ILs, which allow both their recovery and reuse for continuous processing, reducing the overall process cost. Nevertheless, it is important to note that not all ILs are appropriate for biocatalysis, and their proper design is the key for the success of ILs-based biocatalysis. Thus, the activity, specificity and stability of an enzyme in ILs will depend on specific solvent characteristics such as polarity, hydrophobicity, viscosity, hydrogen-bonding capability, solvent miscibility and presence of impurities. ${ }^{14}$ 


\subsection{Ability to establish hydrogen-bonds}

Traditional (solid) salts are able to efficiently pack their constituent ions to form a crystal lattice. As previsously referred, for ILs the cations are asymmetrically substituted with alkyl groups of different chain lengths to prevent packing of the cations/anions into a crystal lattice. ${ }^{1,264} \mathrm{ILs}$ are formed by a widespread network of cations and anions that are connected by both ionic interactions and hydrogen bonds, which are highly significant for the IL organization. ${ }^{62}$ For this reason, ILs are also named "hydrogen-bond polymeric supramolecules". ${ }^{65}$ The insertion of other molecules in that network allows the existence of both polar and non-polar regions within the IL structure. ${ }^{14,30}$ Threedimensional networks in ILs are thus formed due to the establishment of hydrogen bonds between their constituent cations and anions. For example, in imidazoliumbased ILs (such as 1-butyl-3H-benzoimidazolium bis-(trifluoromethylsulfonyl)imide, [BzBIm][NTf2]; 1-butyl-2-phenyl-imidazolium bis(trifluoromethylsulfonyl) imide, [BPhIm][NTf2]; 1-benzyl-3-butyl-imidazolium bis-(trifluoromethylsulfonyl)imide [BnBIm][NTf2]; butyl methyl imidazolium bromide [BMIM]Br; 1-ethyl3-methylimidazolium, 1-butyl-3-methylimidazolium, and 1-octyl-3-methylimidazolium) $)^{66-68}$ each cation interacts with three anions and each anion interacts with three cations, forming a three-dimensional structure. ${ }^{69}$ When a biomacromolecule is placed in contact with such network, polar and non-polar regions are formed resulting in a close interaction between the biomacromolecule and the IL. ${ }^{14,69,70}$ As example, when a protein entity interacts with an IL, the hydrogen-bonded three-dimensional network protects the protein from unfolding. . $^{1,832,71}$

On the other hand, the nucleophilicity of ILs is also determined by their ability to form hydrogen bonds: the greater this ability, the greater is the basicity and the stronger is the nucleophilicity. ${ }^{9,72,73}$ The basicity and nucleophilicity of the hydrogen bonds established with the anions also affects protein stability in IL-based solvents. ${ }^{35,41,74,75}$ In general, anions forming hydrogen bonds with lower basicities and nucleophilicities are more protein-compatible, since low hydrogen bond basicities and nucleophilicities minimize both their interferences with the internal hydrogen bonds in the protein three-dimensional architecture and the interaction with positively charged sites in the protein domain. Thus, the use of these ILs as solvent media for protein can reduce the tendency to occur relevant protein structural changes, ${ }^{41,74-77}$ allowing the stabilization of the protein moiety. ${ }^{34}$ In short, hydrogen bonding could be one of the keys to understanding the interactions between proteins and ILs (see Figure 2).

\subsection{Hydrophilicity/hydrophobicity}

"Hydrophobicity" could be considered as a subset idea of "polarity". It is, however, important to diferentiate the former concept from the latter because the former is often related to the miscibility with water. The hydrophobicity of ILs can be quantified by the $\log \mathrm{P}$ scale. In general, ILs are very hydrophilic (e.g. $\left.\left[\mathrm{C}_{2} \mathrm{mim}\right] \mathrm{C}_{2} \mathrm{H}_{5} \mathrm{SO}_{4},\left[\mathrm{C}_{2} \mathrm{mim}\right] \mathrm{Cl}\right)^{78}$ in nature based on their negative log $\mathrm{P}$ values; nevertheless, by convention, one usually refers to those ILs that are poorly miscible with water as hydrophobic ILs. ${ }^{35}$ Examples $^{78}$ of hydrophobic ILs include 1-ethyl-3-methylimidazolium ([C2mim]) bis-(trifluoromethanesulfonyl) imide ([NTf2]), 1-n-butyl-3-methylimidazolium ([C4mim]) [NTf2], and 1-n-hexyl-3-methylimidazolium ([C6mim]) [NTf2]. Generally, protein entities are more stable in more hydrophobic ILs than in highly hydrophilic ILs. This is due, on one hand, to the fact that hydrophobic ILs do not remove the essential hydration layer of water molecules from the biomacromolecule $\mathrm{e}^{9,34,79,80}$ and, on the other hand, to the fact that in hydrophobic ILs the protein stays in suspended (rather than dissolved, inactive) form. ${ }^{14,77,81}$ Increasing the relative hydrophobicity of ILs increase their stability, activity and enantioselectivity aptitudes over proteins/enzymes. As an example, ILs based on high water-soluble anions (smaller anions, such as chloride) can enter in the protein core, destabilizing the macromolecules structures. ${ }^{82,83}$ On the opposite, ILs highly hydrophobic cause a marked decrease in the rate of enzyme-catalyzed reactions promoted by a thermodynamic stabilization of the substrate(s) to a ground state..$^{35,84-86}$

\subsection{Effects of constituent cations and anions}

Generally, the constituent cations and anions of ILs do play an equal role in stabilizing protein entities. ${ }^{84,87,88}$ As the traditional high melting salts, the ability of ILs to stabilize proteins are generally correlated with the well-known concept of kosmotropicity/chaotropicity. The Hofmeister ion series (a classification of ions in order of their ability to salt-out or salt-in proteins) influences the interaction of cations and anions of different salts with proteins, and such interaction depends on the kosmotropic and chaotropic properties of such cations and anions constituting the ILs. ${ }^{33,39,89}$ This mechanism appears to result from specific interactions between ions and protein moieties, and ions and the water molecules directly contacting the protein moieties may be more important. Kosmotropes (such as, for example, 1-butyl-3-methylimidazolium ([BMIM $\left.\left.]^{+}\right)\right)^{90}$ are considered as structure-maker because they increase the stability of protein entities in solution. On the other hand, chaotropes 
(such as, for example, 1-ethyl-3-methylimidazolium $\left.\left([\mathrm{EMIM}]^{+}\right)\right)^{90}$ are considered structure-breakers since they decrease the stability of proteins in aqueous media. ${ }^{35,91} \mathrm{~A}$ combination of chaotropic (weakly hydrated) cations and kosmotropic (strongly hydrated) anions allows to study the interaction(s) between protein entities and ILs. ${ }^{30,92}$ Anions are highly polarizable, and thus are more prone to hydration than cations are, ${ }^{35,93,94}$ thus exhibiting a more dominating effect and being more efficient than the latter. Mainly, the IL impact on the protein structural conformation seems to be a result of interaction between ILs and the aqueous environment surrounding the protein..$^{15}$ Thus, when a protein molecule is dissolved in an aqueous solution, it has many charged (hydrophilic) groups on its surface responsible for interacting with the ions in solution. ${ }^{34,95}$ Such charged groups strongly interact with chaotropic anions (such as $[\mathrm{SCN}]^{-}$) and kosmotropic cations (such as $\mathrm{Na}^{+}$or $\mathrm{K}^{+}$), ${ }^{41}$ although it is not yet clear how the hydrophobicity of ILs influences the kosmotropicity. ${ }^{35,39}$ However, due to the high number of different interactions that IL ions can establish, their classification as kosmotropic or chaotropic is often quite complex and difficult. . $^{15,96,97}$ Thus, considering the ongoing controversial discussion on the origin of Hofmeister series, Friedman ${ }^{98}$ recommended the use of the expression "specific ion effect" instead of other ambiguous terms such as "Hofmeister effect", "Hofmeister series", "lyotropic effect" and "lyotropic series".

In aqueous solutions, protein molecules might interact with solvent molecules and ions through a diversity of hydrophilic, polar, or charged moieties, like dehydrated, chaotropic amide and amino groups, and the hydrated, kosmotropic carboxyl groups. Chaotropic anions have a greater affinity towards chaotropic amide of the peptide group, while the interaction between kosmotropic cations and the kosmotropic carboxyl moiety is weak due to the presence of water molecules in their nearest hydration shells. This explains the opposite tendency of cations and anions in influencing protein stability, and the stronger effect of anions compared with that of cations. ${ }^{35,39,41}$ However, it is also important to take into consideration that the water molecules "clusters" around the protein are highly significant to correct and maintain the protein function (hydration of the protein backbone), and thus it seems that water also has an important role as mediator of some effects of ILs over proteins. ${ }^{15}$

\subsection{Effects of cation alkyl chain length}

The size of the alkyl chains in the cations of ILs exerts a dramatic effect upon the stability and activity of proteins/ enzymes. Some researchers ${ }^{35,45,99-101}$ have reported that ILs possessing long alkyl chains in their constituent cations induce a destabilizing effect on proteins and, in particular, enzymes. However, some examples can show exactly the opposite behavior. As for example, Jha et al. ${ }^{102}$ have shown unexpected effects of the alteration of structure and stability of myoglobin and hemoglobin in ammoniumbased ILs. In that study, the authors revealed that less viscous ILs carrying smaller alkyl chains induced stronger destabilization of heme protein, maybe due to stronger interactions with hydrophobic regions of the protein. It has been reported that protic ILs, ${ }^{42}$ such as alkylammonium salts, preserve the stability of proteins in aqueous solution at high temperatures, and that amyloid fibrils of proteins (formed by normally soluble proteins, which assemble to form insoluble fibers that are resistant to degradation) are dissolved in protic ILs and become refolded by dilution in aqueous solution. ${ }^{1,32,100,103}$ On the other hand, aprotic ILs act not only as inhibitors of protein aggregation, but also as protective agents for the native, three-dimensional construct of protein entities and accelerate the refolding of thermallydenatured proteins. ${ }^{8}{ }^{814,32,104}$ Huddleston et al. ${ }^{12}$ reported that, notwithstanding their high polarities, most ILs commonly used in biocatalytic processes are hydrophobic in nature due to the presence of large alkyl substituents in the cation molecule(s). For example, 1-hexyl-3-methylimidazolium hexafluorophosphate is more hydrophobic ${ }^{14}$ than 1-butyl3 -methylimidazolium hexafluorophosphate, ${ }^{14}$ and thus more efficient in some biocatalysis.

\section{Relevant Biopharmaceutical Properties of ILs}

ILs are receiving much attention due to their wide range of applications in pharmaceuticals, viz. as solvents for poorly soluble (macro)molecules, drug reservoirs, drug carriers, antimicrobial agents, antibiofilm agents and iono gels (see Figure 3). ${ }^{2,106}$

Several ILs were found to exhibit antimicrobial properties when acting on biofilm-forming Gram-negative pathogenic bacteria such as Pseudomonas aeruginosa (ATCC15692) and Salmonella enterica serovar Typhimurium LT2. ${ }^{64}$ These authors performed a comprehensive study on several synthesized ILs (viz. tetraalkylphosphonium-oleate, tetraalkylphosphonium-hexanoate, tetraalkylphosphoniumgeranate, choline-bistriflimide (NTf2), 1-butyl1-methylpyrrolidinium ((BMP)-NTf2), benzethonium$\mathrm{ZnCl}_{2}$-BMP-NTf2 (BZBN), 1-hexyl-3-methylimidazolium chloride (HMIM-Cl), choline-oleate, choline-hexanoate, choline-geranate, choline-malonate, and choline-urea) reporting their cytotoxicity effects on mammalian cell lines, their skin irritation potential and the properties of 


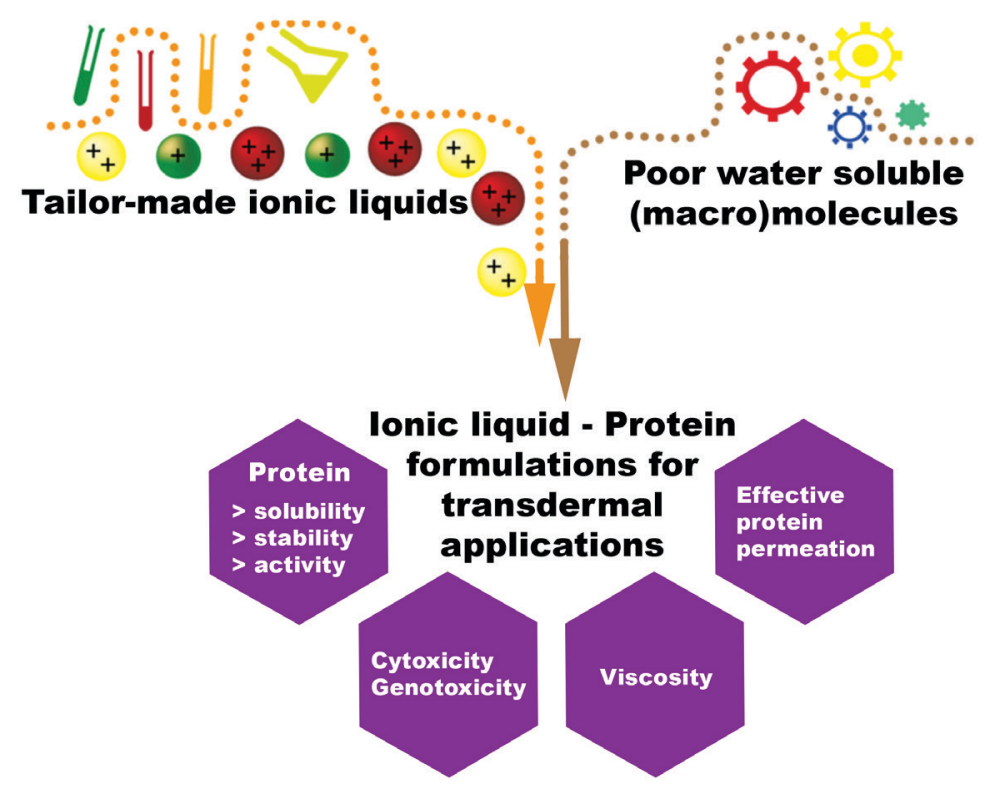

Figure 3. Relationship between ILs and poorly soluble (macro)molecules in the development of IL-protein formulations for transdermal delivery (adapted from reference 105).

those ILs for transdermal drug delivery, and succeeded in treating a biofilm on a skin-wound model. In their work, Zakrewsky et al. ${ }^{64}$ showed that choline geranate acts as a multipurpose compound, exhibiting excellent antimicrobial activity, minimal toxicity to both epithelial cells and skin, and effective permeation enhancement for drug delivery. The biological outcome of ILs, including transdermal delivery, antibacterial activity and cytotoxicity, was attributed to the chemical properties of their constituent cations and anions. ${ }^{64}$ ILs are able to solubilize amphipathic molecules and, in this way, act as ideal solvent systems for topical and transdermal drug delivery (see Figure 3). When compared to traditional organic solvents with small alkyl chains such as ethanol, ILs can be properly designed to be much less toxic to human cells, ${ }^{64,104,107}$ addressing a major issue associated with solvent-induced skin irritation, a typical situation occuring with the application of many topical formulations. Some physicochemical properties of ILs impart them an innate antibacterial activity, most likely because these liquids disrupt both charged and hydrogenbond networks typically found within polypeptides and proteins, polynucleotides and polysaccharides..$^{8,64,108-111}$ Biofilms (or microbial cities) are a major cause of chronic wounds and malignant degeneration, often persisting in the periphery of an actual wound, beneath an intact and healthy skin layer, with the difficulty of their treatment being largely due to the outermost layer of the skin, the stratum corneum, which acts as a natural barrier for drug delivery., ${ }^{9}, 106,112$ A question then arises: when considering ILs as bacterial biofilm control strategies, how "dead bacteria" is really "dead bacteria"? Once the bacterial biofilm is disrupted, the penetration of antibiotics or other antimicrobial moieties is enhanced, leading to restoration of dispersed pathogen cells back to normal antibiotic susceptibility.

\subsection{Use of ILs in transdermal applications}

According to the Centre for Disease Control (CDC), in the United States of America, more than three quarters of all bacterial infections in humans are associated with bacterial biofilms, while more than $65 \%$ of hospital-acquired infections are associated to bacterial biofilms. Biofilms are densely packed communities, or cities, of microbial cells that grow on both living and inert surfaces. When bacteria form biofilms, they secrete and surround themselves with a dense polymeric matrix that makes them 50-1000 times more resistant to treatment with antibiotics. ${ }^{113,114}$ Considering these impressive numbers, it is evident to seek new transdermal delivery systems, which emphasize the full potential that can be triggered by the use of ILs, with massive therapeutic benefits, by simply disrupting bacterial biofilms and facilitating infection targeting by antimicrobial molecules. Transdermal drug delivery systems have been recognized as possible non-invasive routes of drug administration, with several benefits, as for example, avoiding first-pass metabolism, allowing nonstop therapeutic action and better patient acquiescence. Nevertheless, the outmost layer of the epidermis, the stratum corneum, offers an outstanding barrier to the absorption of pharmaceutical compounds, associated to the exceptional ordered structure made up of multiple lipid bilayers and surrounded corneocytes. ${ }^{106,115-117}$ Stratum 
corneum serves as a natural barrier to most therapeutical agents, hiding a protective biofilm that shelters thriving pathogenic bacteria. Under such double-layer, like a protective tent over a colony of harmful bacteria, biofilms make the treatment of skin infections especially difficult, thus making pathogenic bacteria particularly dangerous via enhanced antibiotic resistance..$^{64,106,112,118}$ Traditionally, biofilms and skin barriers have been combated with bleach or other topical formulations, but these tend to irritate the skin and perform poorly as platforms for transdermal drug delivery. Some ILs have therefore arised as a potential "magic" solution for the effective disruption of biofilms, neutralizing pathogens and enhancing the transdermal delivery of antimicrobials into the deeper layers of the skin, while exhibiting minimal (or virtually nil) cytotoxicity effects on human cell lines. ${ }^{2,64,118}$ Such peculiar and highly viscous ILs are able to defeat both the tricky defenses of bacteria (via effective biofilm disruption) and skin (via transient destabilization of the stratum corneum) and, in this way, allow antimicrobial molecules to reach infected sites that otherwise could lead to discomfort, amputations and, sometimes, death. Hence, ILs have the potential to treat chronic wounds and malignant wound, which often result from the onset of bacterial biofilms. Recently, choline geranate emerged as a multipurpose IL since it exhibits excellent antimicrobial activity, ${ }^{64,106,118,119}$ minimal toxicity to epithelial cells as well as to skin, and effectively enhances permeation for transdermal drug delivery. Choline geranate proved to be highly effective in the eradication of established biofilms of Salmonella enterica and Pseudomonas aeruginosa, increasing the delivery of cefadroxil into the deeper tissue layers of the skin without inducing skin irritation. ${ }^{64,118}$ Other approaches of the use of ILs in transdermal applications ${ }^{15}$ were already reported: the use of active pharmaceutical ingredients-ionic liquids (API-ILs), that consists in turning a drug into a salt, a common and easy way to increase the solubility of drugs; ${ }^{120}$ preparation containing fatty acid-based ILs; ${ }^{121}$ assembled formulations composed of drugs and aliphatic carboxylic acids and aliphatic carboxylic amines. ${ }^{122}$

All these studies clearly highlight the potential of ILs for the simultaneous enhancement of topical drug delivery and antibiotic activity. The hunt for new antimicrobial agents has now a new ally which, while protecting and stabilizing bioactive (and potentially antimicrobial) protein entities, enhances their permeation into the deeper layers of the skin (epidermis and dermis) to combat afflictions such as acne, eczema and diabetic ulcers which, otherwise, may get infected and develop an armored layer of bacterial cells (i.e., a bacterial city) that is quite difficult to defeat. While some ILs are intrinsically antimicrobial and others can transport drugs through the layers of the skin, some display both properties, such as choline geranate. The rationale underlying the mechanism of action of ILs is probably linked to the disruption of the polysaccharide-based shell excreted by bacteria that characterize the bacterial cities known as biofilms, although the exact mechanism through which this happens is not fully clear. Hence, a deeper understanding of how ILs disrupt such bacterial biofilms is of utmost importance. Once applied on the surface of the skin, it is likely that the IL molecules slip in between the fatty compounds that make up skin cells, creating transient tiny openings through which bioactive molecules (carried by the IL) can permeate.

\section{Protein Stability and Stabilization in the Presence of ILs}

Folding of proteins and their functional significances are crucial for the existence of a living organism. Their functioning is highly dependent of the maintainance of protein secondary structure ( $\alpha$-helices, $\beta$-sheets and coil regions), which are held together through a complex balance of hydrogen bonds, disulfide bridges, hydrophobic and ionic interactions. ${ }^{51}$ Although the stability of proteins remains as a long-standing unsolved puzzle in protein science, their importance is obvious for biotechnological and medical applications. ${ }^{8}$ Proteins are a particularly heterogeneous class of biomacromolecules which, when displaced from their native (physiological) environments, are frequently quite unstable $34,117,123,124$ due to disruption of the weak interactions (including ionic interactions, hydrogen bonds and hydrophobic interactions) that are primordial for the maintainance of the protein tertiary (three-dimensional) structures. ${ }^{125,126}$ Thus, it is quite obvious that by changing the solvent conditions (such as viscosity, temperature, $\mathrm{pH}$, ionicity, buffering conditions), the protein secondary structure can be significantly affected. ${ }^{51}$ Additionally, despite the unstability of both their structural integrity and activity, it is expected that purified proteins can be stored for extended periods of time. The degree of storage stability may fluctuate from a few days to several months or even years, being highly dependent on the nature of the protein and/or the storage environment.

\subsection{How to counteract protein inactivation}

Protein aggregation is one of the most important problems during production and storage in industrial processes and is, therefore, among the major causes of economic losses in biotechnology and pharmaceutical factories: a variety of proteins, e.g. insulin, coagulation 
factors, interferons and antibodies are currently available for pharmacological treatment of a widespread range of diseases, such as diabetes, hemophilia, multiple sclerosis and cancers. ${ }^{4,123}$ In particular, protein aggregation easily occurs upon exposure of the hydrophobic amino acid moieties, which are usually buried inside the core of the three-dimensional architecture of native proteins, a phenomenon that becomes a major problem due to the fast-irreversible protein inactivation. Thermal denaturation of proteins is a serious problem not only in the separation and storage of proteins, but also during the processes of biotransformation, biosensing, drug production, and food manufacturing. Hence, several strategies have been proposed in order to prevent thermal denaturation of proteins, ${ }^{34,39,106,125,127-136}$ which can include, for example, chemical modification, multipoint covalent immobilization, genetic modification, addition of stabilizing agents, among others. ${ }^{34,106}$ The main goal when manufacturing proteinbased commercial products consists in obtaining a stable and correct protein folding with full functionality. ${ }^{4,8,32,137}$

\subsection{Potential role of ILs in protein stabilization}

ILs have shown excellent promise as both solutes and solvents for stabilizing protein entities at room temperature, ${ }^{14,104,123,125,138}$ or even to be applied as aggregation inhibitors for protein solutions. ${ }^{139}$ Several enzymatic systems have been assessed in neat ILs or IL solutions: such enzymatic structures include numerous hydrolases (e.g. lipases, proteases, thermolysin, $\alpha$-chymotrypsin, lysozyme, $\beta$-glycosidase, cellulase, epoxide hydrolase and penicillin amidase), oxidoreductases (e.g. horseradish peroxidase, alcohol dehydrogenase, laccase and lignin peroxidase) and lyases (e.g. oxynitrilase). ${ }^{35,140}$

Because many advanced (bio)pharmaceuticals are protein-based, namely those from recombinant origin, the stabilizing and solubilizing abilities of ILs show great potential to provide advances in the formulation of liquid solutions of therapeutic proteins. Therapeutics based on proteins (either native or recombinant) has demonstrated significant efficacies in controlling and/or eliminating certain chronic diseases. ${ }^{123}$ Differently from traditional small-molecule-based drug therapies, a substantial hurdle in the development of protein-based (bio)pharmaceuticals is related to the maintenance of the active three-dimensional conformation of the protein entity, not only throughout processing, but also during storage. ${ }^{34,138}$

Since ILs do not exhibit significant vapor pressures, have high thermal stability and a wide range of polarities, ${ }^{8,16}$ they appear as suitable and effective platforms for carrying out advanced biological reactions. In addition, due to their tailoring properties by simply altering the cations (acting on the alkyl chains, either via modification of the length or the presence of hydrophobic groups) and anions (varying either the degree of charge delocalization or its hydrogen bonding ability), ${ }^{3,4,64,141,142}$ ILs can be properly designed and adjusted for a specific biological application. Other IL properties such as melting point, viscosity, density, and hydrophobicity may be also quite valuable, since these may be varied by making simple changes to the structure of the ILs' constituent ions. ${ }^{8,14,125,141,142}$ A high viscosity is probably inherent to ILs, since strong intermolecular forces between their constituent ions promote high viscosity indexes. For ILs, the strong forces prevailing are charge-charge interactions, but weaker interactions such as van der Waals forces also occur between ions. Thus, despite the stronger charge-charge interactions, reducing van der Waals interactions and consequently the surface area of their constituent ions (namely by reducing their size) a slight decrease on the viscosity can be achieved. ${ }^{14,76,142}$ The ability to modulate the individual components making up ILs presents an advantageous framework for tuning secondary and tertiary physicochemical characteristics of protein entities without losing their primary function. ${ }^{8,58}$

\subsection{Protein-IL interactions}

The problems of protein aggregation and structural stability are not limited to the manufacturing processes, though. Several research works are focused in the study of the ability of ILs to in vitro solubilize and stabilize proteins for extended periods of time, ${ }^{123,143-145}$ by reverting some aggregation processes and improving the in vitro refolding of denatured proteins., ${ }^{4,1432,140,146,147}$ Recently, Balcão and Vila $^{34}$ have suggested that the rationale underlying the stabilizing effect of protein entities due to an increased viscosity of their surrounding nanoenvironment is, in fact, the slowing down of the migration of protein domains from the active conformation into the inactive one. The decrease of overall dynamics of the solvent and dissolved protein by the increase of viscosity is a key for the stabilization of proteins, and thus, this mechanism is in total agreement with the high viscosity of ILs and their protein-stabilizing properties. . $^{1,140,142}$

For low hydration levels of ILs, however, and particularly in the case of short-chained hydrophilic ILs, there is a large disturbance in the protein's three-dimensional architecture. Notably, hydrophilic ILs are thought to act as denaturants for several globular proteins only at high concentrations. 14,39,140,148 The essential shell of water molecules for protein hydration is stripped off from the protein entity by small-chained hydrophilic solvents, leading to unfolding of the biomolecule 
and concomitant exposure of the core hydrophobic residues, whereas hydrophobic solvents keep the protein moiety flexible and in active conformation, ${ }^{1,32,34,35,125,149}$ with the hydrophobic residues buried deep inside its core. On the other hand, the interactions of protein moieties with ILs are dominated by Coulomb interactions with anions, with the second largest contribution stemming from van der Waals interactions with cations. The strength of the protein-ion interaction is largely determined by both the size of the ion and the magnitude of the surface charge of the ion. ${ }^{8,140,150}$ The rationale underlying the mechanism for protein stabilization in ILs is interesting. Basically, the protein stabilization using ILs arises from their solubility, polarity and viscosity effects, which is in clear agreement with the work published by Balcão and Vila. ${ }^{34}$ However, it is important to note that the protein can be stabilized or destabilized. As example, the high polarity can reduce the water associated with protein, but at the same time due to the high-water content in the bulk phase the viscosity is reduced, increasing consequently the protein mobility (and its biological activity). ${ }^{151}$ The enhanced stability of proteins in ILs such as 1-butyl-3-methylimidazolium chloride ([Bmim] $\mathrm{Cl}$ ) rules out the prediction that these ILs are also denaturants or destabilizers for the protein structure. ${ }^{152,153}$ Since ILs containing small halide anions generally exhibit strong electrostatic interactions due to the small anion radius, they are effective for protein dissolution. ${ }^{140,154}$ Likely, the interaction of the ions with the hydrophilic or hydrophobic amino acid moieties of the protein entity is much more significant than ion-induced long-range disruption of the surrounding water structure. . $^{1,35,125,140,155}$

The biomolecular interactions between ILs and protein entities are, thus, complex, with all the current scientific literature ending at the similar conclusion that the stabilization/destabilization of the protein entities depends on the selectivity between ILs and proteins. Such consensus requires, of course, additional research. Baker and Heller ${ }^{156}$ showed that the interaction between protein moieties and ILs not only caused significant unfolding of the (secondary domain) $\alpha$-helical structures of the protein moieties, but also changed their aggregation state, suggesting that the aforementioned interaction depends on the protein sequence. Additionaly, the type of ILs ions does play an important role in affecting the protein biological and conformational structure, presumably either by direct interaction with the protein moieties or by modification of the microenvironment in, and around, the protein moiety, due to their different physicochemical properties. ${ }^{84,157}$ Notwithstanding the fact that the anions in ILs are significant for the protein stabilization, the contributing effect of the alkyl chain in the cation cannot be ignored. ${ }^{39,158}$
When the protein entity is in an aqueous environment, the role of the (aqueous) solvent in the stabilization of the protein structure is of utmost importance, ${ }^{34}$ making it important to understand the rearrangement of solvent molecules (water) in the presence of co-solutes (as for example ILs) at a molecular level (see Figure 2). In the liquid state, water displays asymmetry between the donor and acceptor in hydrogen bonding, ${ }^{1,159}$ with the difference in the orientation of water molecules towards polar/ apolar solutes being one of the factors responsible for the solubility behavior of a given solute in aqueous medium, thus playing a major role in the structure, stabilization and function of biological macromolecules. ${ }^{8,34}$ The effects of both polar and apolar solutes upon water structure has been duly reviewed by Sharp and Vanderkool, ${ }^{160}$ where they tackled the structure and solvation of water molecules, where the water is a highly cohesive and interacting three-dimensional network of hydrogen bonding groups. A weakly interacting apolar moiety can only insert itself by displacing the weaklier coordinated water molecules that produce larger hydrogen bond angles. On the other hand, polar groups with their strong electrostatic fields tend to align solvating water molecules in a way that they make more strained hydrogen bonding with each other. ${ }^{1,35,125,161,162}$ Thus, direct electrostatic interactions occur between protein hydrophilic groups, as a result of the dieletric shielding between proteins provided by the hydrogen-bond networks. ${ }^{15,163-165}$ Overall, if the hydrogen bonding between water molecules is weaker, they are more labile to disruption by temperature and solutes. ${ }^{125,160,166,167}$ Water has long been thought as the unique solvent for biomolecules and biosystems, since it is fundamental in protein folding mainly because of its role in defining hydrophobic attractions ${ }^{168}$ that are responsible for the rapid gluing of hydrophobic sites. Long ago, Luscher and Ruegg ${ }^{169}$ proposed a model for the interaction of water molecules with the native protein three-dimensional architecture, with the experimental results suggesting that the interaction between the first monolayer of water molecules with the surface of the protein is responsible for major conformational changes in the native structure of the protein molecule. ${ }^{170,171}$ Such arrangement of water molecules surrounding the protein surface was then designated to be the hydration shell., 1,35,125,172-174 The formation of the hydration layer is mainly responsible for the large values in excluded volume for the proteins in the presence of stabilizing agents. ${ }^{175-177}$ On the contrary, denaturing agents promote large fluctuations in the hydration layer of water molecules that can prevent protein dynamics, affecting its function. ${ }^{178,179}$ The presence of solutes also disturbs the angular structure of water. ${ }^{160,180}$ 
When talking about ILs and water, their interactions are far more complex and are highly dependent on the nature of ILs' constituent ions. According to the law of matching affinities postulated by Collins, ${ }^{181}$ the nature of the cationanion interactions in an ionic compound is also responsible for the change in protein stability in ionic solutions. According to the Collins' rationale, ${ }^{181}$ stabilization and crystallization of proteins are both related with a decrease in the solvent accessibility to the protein surface, while with the increase of solvent-surface protein accessibility causes destabilization and solubilization. Collins ${ }^{181}$ demonstrated that combinations of chaotropic-chaotropic or kosmotropic-kosmotropic cation-anion lead to weak ionswater molecules interactions, since the oppositely charged ions of the dissolved ionic compound tend to stay together. While the miscibility behavior with water is simply related to the hydrophobicity of the cation (or to the hydrophobicity of the anion, in this case reducing the water solubility of the ILs), such behavior is more complex for ILs with varying anions, due to pronounced anion-water interactions. ${ }^{21,39}$ The interaction of ILs with the protein surface is a complex result of the ability of their ions to disrupt the hydrogen bonding, to promote non-polar interactions, and to induce electrostatic effects that contribute to protein stability. ILs are thus considered as interesting solvents for biological systems and, due to their unique properties and large variety of potential applications, they have been widely used in enzyme catalysis and protein stabilization, solubilization, crystallization and separations.

Protein entities are one of the most important biomacromolecules of living beings, possessing highly relevant clinical, biochemical, biotechnological and genetic features. As protein entities exhibit admirable biological properties, their production and applications have grown very rapidly in different fields such as in biochemical research, chemical, food and (bio)pharmaceutical industries. ${ }^{1,34,35,39,84,123,152}$ Due to the wide range of their potential applications, it is fundamental to maintain the three-dimensional architecture of protein moieties through weak interactions such as hydrogen bonds, and hydrophobic and electrostatic interactions. Small changes in the protein microenvironment disrupt such weak interactions causing their denaturation, which in turn leads to the unfolding of the three-dimensional architecture and concomitant inactivation. ${ }^{126,129,152,182}$ To overcome these issues, several strategies to stabilize proteins outside their native (physiological) conditions have been developed, ${ }^{34}$ such as, chemical modification, immobilization (either via entropic confinement or through establishment of multipoint covalent bonding to macroscopic insoluble supports), genetic modification, or addition of stabilizing agents, while the protein is still in its native (active) threedimensional conformation. Some of these strategies are quite effective, however, do not prevent the irreversible thermal denaturation of proteins. . $^{35,130,132,133}$ The half-lives of many proteins, including therapeutic ones, can be increased by lyophilization (freeze-drying) ${ }^{34}$ In order to increase the solubility and to prevent denaturation and aggregation of therapeutic proteins, some excipients like sugars, salts and amino acids have been used in commercial formulations. ${ }^{34,125}$ However, such excipients also fail to provide reasonable long-term stability to some therapeutic proteins. ${ }^{35,138}$ Considering these assumptions, ILs have been emerging as very feasible solvents either for performing enzymatic reactions ${ }^{123,183,184}$ or for other protein-based applications. ${ }^{185-187}$ Although ILs are capable of stabilizing protein entities over a wide range of temperatures, the thermal stability of these biomacromolecules depends on the correct choice of ILs employed, since proteins are not homogeneously stable in all ILs-classes. In general, proteins' stability and activity are mainly affected by polarity, hydrophobicity and hydrogen-bonding capability of ILs ions. Thus, it is evident that the solubility and stability of protein entities in ILs heavily depends on the type of cation and anion. ILs containing chaotropic cations (bulky, low-charged and weakly-hydrated ions that decrease the structure of water) and kosmotropic anions (small-sized, highly-charged and strongly-hydrated ions that increase the structure of water) are described as optimal biomacromolecules stabilizers. ${ }^{39,125,174,181,187}$ ILs enhance protein stability, maintaining their threedimensional structure ${ }^{188}$ and, due to their high solvation capability, enabling the solubilization of protein entities. Upon solubilization in ILs, protein aggregation is prevented, which contributes thereby to the increase in the stability and biological activity of the protein. ${ }^{35,188}$ Several researchers ${ }^{145,148,189}$ demonstrated that the hydrophobic IL 1-butyl-3-methylpyridinium bis(trifluoromethylsulfonyl) imide ([BMPy][NTf2]) can be used to dissolve a small amount of the protein monellin. Other published papers $^{35,140,190,191}$ report the use of additional structures to stimulate protein solubilization in hydrophobic ILs.

These features of ILs have helped in preparing liquid formulations of therapeutic proteins, which is actually one of the major hurdles in the use of protein-based therapeutics. Such biocompatible ILs solvate and stabilize therapeutic proteins, opening up a new window in the (bio) pharmaceutical industry. ${ }^{35,123,138,192,193} \mathrm{~A}$ potential rationale for the mechanism underlying the increased protein solubility in ILs could be the replacement of a hydrophobic site in the protein moiety with an ion from the IL and concomitant reduction of the likelihood that site would subsequently 
participate in nonspecific interactions. If the formation of structured crystals is regarded as a kinetic process, where the rate of formation of amorphous precipitate competes with that for formation of crystalline structures, then raising the solubility or reducing nonspecific binding between hydrophobic sites would effectively slow down the protein self-aggregation processes, leading to enhanced stability. ILs can also be used as alternative reaction media solvents for biocatalysis and biotransformation reactions, ${ }^{8,76}$ with several researchers $5,17,43,76,77,80,194-202$ demonstrating that ILs play an important role in increasing the activity, stability and enantioselectivity of enzymes. The enhancement observed in the activity and stability of protein entities seems to be associated with both maintenance of $50 \%$ of the initial $\alpha$-helix content and the enhancement of $\beta$-strands of the enzyme molecule at $50{ }^{\circ} \mathrm{C}$, resulting in a more compact enzyme conformation while still being able to display catalytic activity. ${ }^{144}$ Potdar et al. ${ }^{203}$ provided an overview with special emphasis on the application of enzyme-catalyzed reactions and separation processes employing ILs. ILs are, therefore, effective in increasing enzyme (thermal) stability and selectivity and maintain a high enzymatic efficiency with greater reaction rates at high substrate concentrations, and with shorter reaction times. . $^{8,39,106,204}$

\section{Future Trends}

Advances in the field of structural and functional stabilization of protein entities, such as enzymes, recombinant proteins, bioactive peptides, bacteriophage particles, or protein-based antibiotics, using tailor-made ILs, will enable not only the solubilization and stabilization of those entities, but also their incorporation into liquid formulations for biopharmaceutical applications. Bearing in mind that all protein entities share common features related to their intrinsic instability when put in environments displaced from their native physiological conditions, and because the latest advances in biopharmaceutical production allows guessing an increase in the use of protein-based biopharmaceuticals, full structural and functional stabilization of said biomolecules will be of utmost importance. In this line of thinking, although ILs can exert both stabilizing (by solubilizing protein moieties, thus preventing their self-aggregation) and destabilizing effects on protein moieties, depending on their physico-chemical properties, tailoring of such highly viscous liquid salts to less viscous, hydrophobic ones, containing chaotropic cations and kosmotropic anions, will allow to optimally stabilize protein entities up to a wide range of temperatures and for extended periods of time.

\section{Acknowledgments}

Project funding by Fundação de Amparo à Pesquisa do Estado de São Paulo (FAPESP, São Paulo, Brazil) (FAPESP Refs. No. 2016/08884-3 (Project PneumoPhageColor) and 2016/12234-4 (Project TransAppIL)) is hereby gratefully acknowledged. Funding by Fundação de Amparo à Pesquisa do Estado de São Paulo (FAPESP Ref. No. 2016/16641-3) in the form of an MSc fellowship granted to Liliam Harada is hereby gratefully acknowledged. This work also received support from CNPq, National Council for Scientific and Technological Development, Brazil, in the form of Research Productivity (PQ) fellowships granted to Victor M. Balcão (Refs. No. 306113/2014-7 and 308208/2017-0).

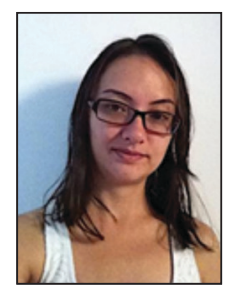

Liliam K. Harada holds a degree in Pharmacy from the University of Sorocaba (2010). She has experience in the field of Pharmacy, with emphasis on allopathic, homeopathic and anthroposophical manipulation, as well as training in floral therapy, and post graduation in acupuncture. She completed a master's degree in Pharmaceutical Sciences from the University of Sorocaba, with a scholarship awarded by FAPESP (Ref. No. 2016/16641-3), and is currently developing research projects leading to the doctor degree, aiming at the development of a biosensor based in phage particles for the detection of Pseudomonas aeruginosa.

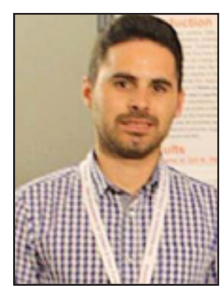

Jorge F. B. Pereira is since July 2014, Assistant Professor of the Department of Bioprocesses and Biotechnology of the Faculty of Pharmaceutical Sciences, Universidade Estadual Paulista (Unesp, Araraquara) and professor accredited in the Postgraduate Program in Biosciences and Biotechnology applied to Pharmacy (CAPES 7). He holds a Doctor of Chemical Engineering degree from the Department of Chemistry of the University of Aveiro (2009-2013). The main areas of activity are focused on the development of alternative separation and purification processes for the purification of biopharmaceuticals using ionic liquids; and study of molecular interactions of separation processes using ionic liquids.

Welida F. Campos holds a degree in Bioprocess Engineering and Biotechnology from the University of Sorocaba (Uniso, 2017). For 11 months, she developed 


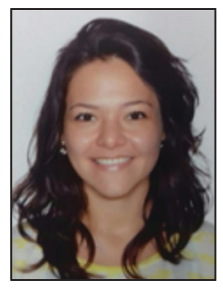

her research activities at the Laboratory of Biofilms and Bacteriophages (PhageLab, Uniso) in the scope of her undergraduate thesis, currently continuing as a Master's Student in Pharmaceutical Sciences in the same Laboratory. Her research project aims at the isolation and purification of bacteriophage particles aiming at their transdermal permeation using ionic liquids for the eradication of deep skin infections.

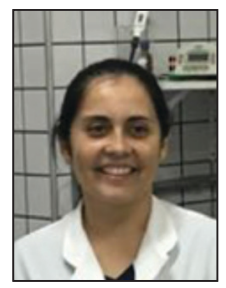

Erica C. Silva holds a degree in Bioprocess Engineering and Biotechnology from the University of Sorocaba (Uniso, 2017). For 11 months, she developed her research activities at the Laboratory of Biofilms and Bacteriophages (PhageLab, Uniso) in the scope of her undergraduate thesis, currently continuing as a Master's Student in Pharmaceutical Sciences in the same Laboratory. Her research project aims at the isolation and purification of bacteriophage particles aiming at their incorporation in IL/O microemulsions for the eradication of skin infections in veterinary applications.

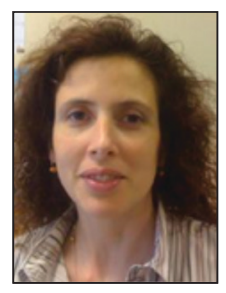

Carla S. G. Moutinho graduated in Pharmaceutical Chemistry from the University of Porto in 2000. She is an Associate Professor at University Fernando Pessoa (Porto, Portugal). She has published 38 articles in specialized magazines and 49 works in event proceedings, has 2 book chapters and 3 books published. She participated in 52 events abroad and two in Portugal. She works in the areas of Medical Sciences with emphasis on Health Sciences and Exact Sciences with emphasis on Chemistry, specifically with anti-neoplastics, liposomes, mixed micelles, fatty acids, antioxidants, beta-blockers and benzodiazepines, and micellar systems (mixed and simple).

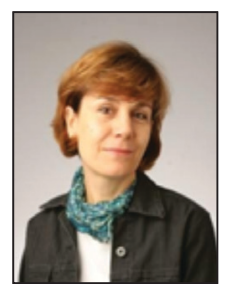

Marta M. D. C. Vila holds a bachelor's degree in Pharmacy and Biochemistry from the University of São Paulo (1984), a degree in Industrial Pharmacy from the Pontifical Catholic University of Campinas (1985), a Master's degree in Food Technology from the State University of Campinas (1996) and a PhD in Chemistry from the State University of Campinas (2002). She is a lecturer at the University of Sorocaba (Uniso) in the Graduate Program in Pharmaceutical Sciences. She has developed projects related to the study of new formulations, bioavailability of active principles and new systems of drug release.

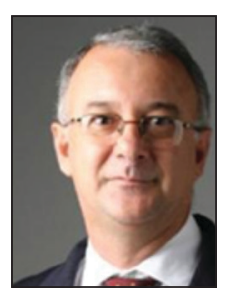

José M. Oliveira Jr. is a bachelor in Physics from the State University of Londrina (1985), Master in Nuclear Physics from the University of São Paulo (1988) and PhD in Sciences, with emphasis in Nuclear Physics by the University of São Paulo (1994). Currently holds the position of Pro-Rector of Postgraduate, Research, Extension and Innovation of the University of Sorocaba. He is full professor of the Postgraduate Program in Pharmaceutical Sciences. He has worked mainly in the study of nuclear reactions and spectroscopic properties of exotic nuclei; use of CT technique and attenuation of gamma radiation and $X$-rays in non-destructive studies of biological materials and systems.

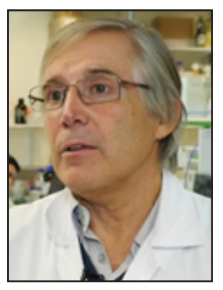

José A. Teixeira holds a degree in Chemical Engineering from the University of Porto (1980) and a PhD in Chemical Engineering from the Faculty of Engineering of the University of Porto (1988). He is currently Professor at the Biological Engineering Department of the University of Minho, Braga, Portugal. He has experience in Chemical Engineering, with emphasis in Chemical Engineering and Biotechnology, working mainly in the following subjects: biological reactors, multiphase systems, food technology, biological separation processes.

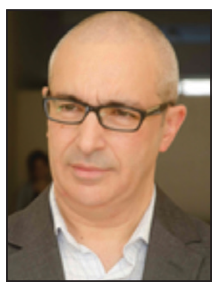

Victor M. Balcão is an Adjunct Professor I, RG at the University of Sorocaba (Brazil), where he also coordinates the Laboratory of Biofilms and Bacteriophages (PhageLab), being a Productivity in Research fellow, level 2, of CNPq (308208/2017-0). He graduated in 1991 in Food Engineering from the College of Biotechnology of the Portuguese Catholic University (ESB-UCP), and received a doctorate in Biotechnology in 12/1998 from ESB-UCP. On 04/11/2013, he obtained Recognition of the Doctor degree from University of São Paulo (Diploma registered under number 116247, Article 48 of Law 9394/96). Its scientific activity has focused on the structural and functional stabilization of protein entities for (bio)pharmaceutical applications. 


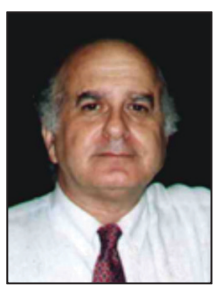

Matthieu Tubino holds a Bachelor's Degree in Chemistry from the University of São Paulo (1970), a Master's Degree in Chemistry from the State University of Campinas (1975), a PhD in Chemistry from the State University of Campinas (1978), postdoctoral degree from Institut de Chimie Minérale et Analytique of the Universite de Lausanne, Switzerland. He is a full professor at the Institute of Chemistry of the State University of Campinas. He has experience in reaction mechanisms, diffuse reflectance analysis in ultraviolet-visible, analytical methods for application in industrial matrices including biodiesel.

\section{References}

1. Zhou, L.; Tian, T.; Xiao, J.; Wang, T.; Yu, T.; J. Mol. Liq. 2017, 225,50 .

2. Goindi, S.; Kaur, R.; Kaur, R.; Int. J. Pharm. 2015, 495, 913.

3. Ghandi, K.; Green Sustainable Chem. 2014, 4, 44.

4. Mangialardo, S.; Gontrani, L.; Leonelli, F.; Caminiti, R.; Postorino, P.; RSC Adv. 2012, 2, 12329.

5. Moniruzzaman, M.; Nakashima, K.; Kamiya, N.; Goto, M.; Biochem. Eng. J. 2010, 48, 295.

6. Ferraz, R.; Branco, L. C.; Prudêncio, C.; Noronha, J. P.; Petrovski, Z.; ChemMedChem 2011, 6, 975.

7. Gouveia, W.; Jorge, T. F.; Martins, S.; Meireles, M.; Carolino, M.; Cruz, C.; Almeida, T. V.; Araújo, M. E.; Chemosphere 2014, $104,51$.

8. Kumar, A.; Bisht, M.; Venkatesu, P.; Int. J. Biol. Macromol. 2017, 96, 611

9. Nor, S.; Woi, P.; Ng, S.; J. Mol. Liq. 2017, 234, 30.

10. Tokuda, H.; Ishii, K.; Susan, M. A. B. H.; Tsuzuki, S.; Hayamizu, K.; Watanabe, M.; J. Phys. Chem. B 2006, 110, 2833.

11. Zhang, S.; Sun, N.; He, X.; Lu, X.; Zhang, X.; J. Phys. Chem. Ref. Data 2006, 35, 1475.

12. Huddleston, J. G.; Visser, A. E.; Reichert, W. M.; Willauer, H. D.; Broker, G. A.; Rogers, R. D.; Green Chem. 2001, 3, 156.

13. Bonhôte, P.; Dias, A. P.; Papageorgiou, N.; Kalyanasundaram, K.; Grätzel, M.; Inorg. Chem. 1996, 35, 1168.

14. Piotrowska, U.; Sobczak, M.; Molecules 2015, $20,1$.

15. Egorova, K. S.; Gordeev, E. G.; Ananikov, V. P.; Chem. Rev. 2017, 117, 7132.

16. Welton, T.; Chem. Rev. 1999, 99, 2071.

17. Wasserscheid, P.; Keim, W.; Angew. Chem., Int. Ed. 2000, 39, 3772.

18. Zhao, D.; Wu, M.; Kou, Y.; Min, E.; Catal. Today 2002, 74, 157.

19. van Rantwijk, F.; Sheldon, R. A.; Chem. Rev. 2007, 107, 2757.

20. Plechkova, N. V.; Seddon, K. R.; Chem. Soc. Rev. 2008, 37, 123.
21. Weingärtner, H.; Angew. Chem., Int. Ed. Engl. 2008, 47, 654.

22. Hallett, J. P.; Welton, T.; Chem. Rev. 2011, 111, 3508.

23. Mallakpour, S.; Dinari, M. In Green Solvents II: Properties and Applications of Ionic Liquids; Mohammad, A.; Inamuddin, D., eds.; Springer-Verlag: Berlin-Heidelberg, Germany, 2012, ch. 1, p. 1-32.

24. Chatel, G.; Pereira, J. F. B.; Debetti, V.; Wang, H.; Rogers, R. D.; Green Chem. 2014, 16, 2051.

25. Passos, H.; Freire, M. G.; Coutinho, J. A.; Green Chem. 2014, $16,4786$.

26. Almeida, T. S.; Júlio, A.; Mota, J. P.; Rijo, P.; Reis, C. P.; Ther. Delivery 2017, 8, 461 .

27. Consorti, C. S.; de Souza, R. F.; Dupont, J.; Suarez, P. A. Z.; Quim. Nova 2001, 24, 830.

28. Lehn, J.-M.; Supramolecular Chemistry: Concepts and Perspectives; VCH: Weinheim, 1995.

29. Kunz, W.; Häckl, K.; Chem. Phys. Lett. 2016, 661, 6.

30. Shu, Y.; Lu, J.; Mao, Q.; Song, R.; Wang, X.; Chen, X.; Wang, J.; Carbon 2017, 114, 324.

31. Pal, A.; Yadav, A.; J. Mol. Liq. 2016, 222, 471.

32. Ghosh, S.; Dey, S.; Patela, M.; Chakrabarti, R.; Phys. Chem. Chem. Phys. 2017, 19, 772.

33. Johnson, L.; Park, S.; Gintner, L.; Snow, C.; J. Mol. Catal. B: Enzym. 2016, 132, 84.

34. Balcão, V. M.; Vila, M. M. D. C.; Adv. Drug Delivery Rev. 2015 , 93, 25.

35. Zhao, H.; J. Chem. Technol. Biotechnol. 2016, 91, 25.

36. Kumar, A.; Venkatesu, P.; Int. J. Biol. Macromol. 2014, 63, 244.

37. Quijano, G.; Couvert, A.; Amrane,A.; Darracq, G.; Couriol, C.; Le Cloirec, P.; Paquin, L.; Carrié, D.; Chem. Eng. Sci. 2011, 66, 2707.

38. Kundu, K.; Paul, B. K.; Bardhan, S.; Saha, S. K. In Ionic Liquid - Based Surfactant Science; Paul, B. K.; Moulik, S. P., eds.; 2015, ch. 20, DOI: 10.1002/9781118854501.

39. Todinova, S.; Guncheva, M.; Yancheva, D.; J. Therm. Anal. Calorim. 2016, 123, 2591.

40. Collins, R. D.; Washabaugh, M. W.; Q. Rev. Biophys. 1985, 18, 323.

41. Zhao, H.; J. Chem. Technol. Biotechnol. 2010, 85, 891.

42. Summers, C. A.; Flowers, I. I. R. A.; Protein Sci. 2000, 9, 2001.

43. de Diego, T.; Lozano, P.; Gmouh, S.; Vaultier, M.; Iborra, J. L.; Biotechnol. Bioeng. 2004, 88, 916.

44. Gordon, C. M.; Appl. Catal., A 2001, 222, 101.

45. Mann, J. P.; McCluskey, A. M.; Atkin, R.; Green Chem. 2009, 11,785 .

46. Lozano, P.; de Diego, T.; Carrie, D.; Vaultier, M.; Iborra, J. L. In ACS Symposium Series, vol. 856; Rogers, R. D.; Seddon, K. R., eds.; American Chemical Society: Washington, DC, USA, 2003, ch. 20, p. 239.

47. Wei, W.; Danielson, N. D.; Biomacromolecules 2011, 12, 290.

48. Bihari, M.; Russell, T. P.; Hoagland, D. A.; Biomacromolecules 2010, 11, 2944. 
49. Akdogan, Y.; Junk, M. J. N.; Hinderberger, D.; Biomacromolecules 2011, 12, 1072.

50. Zhao, H.; Olubajo, O.; Song, Z.; Sims, A. L.; Person, T. E.; Lawal, R A.; Holley, L. A.; Bioorg. Chem. 2006, 34, 15.

51. Schröder, C.; Top Curr. Chem. 2017, 375, 25.

52. Lee, S. H.; Doan, T. T. N.; Ha, S. H.; Chang, W.-J.; Koo, Y.-M.; J. Mol. Catal. B: Enzym. 2007, 47, 129.

53. Dobler, D.; Schmidts, T.; Klingenhöfer, I.; Runkel, F.; Int. J. Pharm. 2013, 441, 620.

54. Gilmore, B. F. In Ionic Liquids: Applications and Perspectives; Kokorin A., ed.; InTech; Rijeka, Croatia, 2011, ch. 26.

55. Moniruzzaman, M.; Tamura, M.; Tahara, Y.; Kamiya, N.; Goto, M.; Int. J. Pharm. 2010, 400, 243.

56. Smith, K. B.; Bridson, R. H.; Leeke, G. A.; J. Pharm. Pharmacol. 2010, 62, 1412.

57. Prausnitz, M. R.; Langer, R.; Nat. Biotechnol. 2008, 26, 1261.

58. Hough, W. L.; Smiglak, M.; Rodríguez, H.; Swatloski, R. P.; Spear, S. K.; Daly, D. T.; Pernak, J.; Grisel, J. E.; Carliss, R. D.; Soutullo, M. D.; Davis Jr., J. H.; Rogers, R. D.; New J. Chem. 2007, 31, 1429.

59. Dean, P. M.; Pringle, J. M.; MacFarlane, D. R.; Phys. Chem. Chem. Phys. 2010, 12, 9144

60. Caparica, R.; Júlio, A.; Mota, J. P.; Rosado, C.; de Almeida, T. S.; J. Pharmacol. Clin. Res. 2018, 4, 555649.

61. Adawiyah, N.; Moniruzzaman, M.; Hawatulaila, S.; Goto, M.; Med. Chem. Commun. 2016, 7, 1881.

62. Hayes, R.; Warr, G. G.; Atkin, R.; Chem. Rev. 2015, 115, 6357.

63. Greaves, T. L.; Drummond, C. J.; Chem. Rev. 2008, 108, 206.

64. Zakrewsky, M.; Lovejoy, K. S.; Kern, T. L.; Miller, T. E.; Le, V.; Nagy, A.; Goumas, A. M.; Iyer, R. S.; Del Sesto, R. E.; Koppisch, A. T.; Fox, D. T.; Mitragotri, S.; Proc. Natl. Acad. Sci. U. S. A. 2014, 111, 13313.

65. Craig, S. L.; Angew. Chem., Int. Ed. Engl. 2009, 48, 2645.

66. Kermanioryani, M.; Mutalib, M. I. A.; Dong, Y.; Lethesh, K. C.; Ghanem, O. B. O. B.; Kurnia, K. A.; Aminuddin, N. F.; Leveque, J.-M.; J. Chem. Eng. Data 2016, 61, 2020.

67. Thierry, M.; Majira, A.; Pégot, B.; Cezard, L.; Bourdreux, F.; Clément, G.; Perreau, F.; Boutet-Mercey, S.; Diter, P.; Vo-Thanh, G.; Lapierre, C.; Ducrot, P.-H.; Magnier, E.; Baumberger, S.; Cottyn, B.; ChemSusChem 2018, 11, 439.

68. Satish, L.; Rana, S.; Arakha, M.; Rout, L.; Ekka, B.; Jha, S.; Dash, P.; Sahoo, H.; Spectrosc. Lett. 2016, 49, 383.

69. Dupont, J.; J. Braz. Chem. Soc. 2004, 15, 341.

70. Schroder, U.; Wadhawan, J. D.; Compton, R. G.; Marken, F.; Suarez, P. A. Z.; Consorti, C. S.; de Souza, R. F.; Dupont, J.; New J. Chem. 2000, 24, 1009.

71. Lozano, P.; de Diego, T.; Gmouh, S.; Vaultier, M.; Iborra, J. L.; Biocatal. Biotransform. 2005, 23, 169.

72. MacFarlane, D. R.; Pringle, J. M.; Johansson, K. M.; Forsyth, S. A.; Forsyth, M.; Chem. Commun. 2006, 0, 1905.
73. Rogers, R. D.; Seddon, K. R.; Volkov, S.; Green Industrial Applications of Ionic Liquids, NATO Science Series II: Mathematics, Physics and Chemistry, vol. 92; Kluwer Academic Publisher: Dordrecht, Netherlands, 2002.

74. Anderson, J. L.; Ding, J.; Welton, T.; Armstrong, D. W.; J. Am. Chem. Soc. 2002, 124, 14247.

75. Armstrong, D. W.; He, L.; Liu, Y.-S.; Anal. Chem. 1999, 71, 3873.

76. Park, S.; Kazlauskas, R. J.; Curr. Opin. Biotechnol. 2003, 14, 432.

77. Sheldon, R. A.; Madeira Lau, R.; Sorgedrager, M. J.; van Rantwijk, F.; Seddon, K. R.; Green Chem. 2002, 4, 147.

78. Yee, P.; Shah, J. K.; Maginn, E. J.; J. Phys. Chem. B 2013, 117, 12556.

79. Laszlo, J. A.; Compton, D. L.; Biotechnol. Bioeng. 2001, 75, 181.

80. Yang, Z.; Pan, W.; Enzyme Microb. Technol. 2005, 37, 19.

81. Erbeldinger, M.; Mesiano, A. J.; Russell, A. J.; Biotechnol. Prog. 2000, 16, 1129.

82. Latif, M. A.; Tejo, B. A.; Abedikargiban, R.; Abdul Rahman, M. B.; Micaêlo, N. M.; J. Biomol. Struct. Dyn. 2014, 32, 1263.

83. Latif, M. A. M.; Micaêlo, N. M.; Abdul Rahman, M. B.; RSC Adv. 2014, 4, 48202.

84. Qamar, S.; Brown, P.; Ferguson, S.; Khan, R.; Ismail, B.; Khan, A.; Sayed, M.; Khan, M.; J. Colloid Interface Sci. 2016, 481, 117.

85. Ryu, K.; Dordick, J. S.; Biochemistry 1992, 31, 2588.

86. Lou, W.-Y.; Zong, M.-H.; Wu, H.; Xu, R.; Wang, J.-F.; Green Chem. 2005, 7, 500.

87. El-Hady, D.; Albishri, A.; Rengarajan, R.; Deeb, S.; Wätzig, H.; Electrophoresis 2015, 36, 3080.

88. Baker, S. N.; Zhao, H.; Pandey, S.; Heller, W. T.; Bright, F. V.; Baker, G. A.; Phys. Chem. Chem. Phys. 2011, 13, 3642.

89. Hofmeister, F.; Arch. Exp. Pathol. Pharmakol. 1888, 24, 247.

90. Zhao, H.; J. Chem. Technol. Biotechnol. 2006, 81, 877.

91. Eggers, D. K.; Valentine, J. S.; J. Mol. Biol. 2001, 314, 911.

92. Yang, Z.; J. Biotechnol. 2009, 144, 12.

93. Grossfield, A.; Ren, P. Y.; Ponder, J. W.; J. Am. Chem. Soc. 2003, 125, 15671.

94. Combariza, J. E.; Kestner, N. R.; Jortner, J.; J. Chem. Phys. 1994, 100, 2851.

95. Sedlak, E.; Stagg, L.; Wittung-Stafshede, P.; Arch. Biochem. Biophys. 2008, 479, 69.

96. Benedetto, A.; Ballone, P.; Philos. Mag. 2016, 96, 870.

97. Tietze, A. A.; Bordusa, F.; Giernoth, R.; Imhof, D.; Lenzer, T.; Maass, A.; Mrestani-Klaus, C.; Neundorf, I.; Oum, K.; Reith, D.; Stark, A.; Chem. Phys. Chem. 2013, 14, 4044.

98. Friedman, R.; J. Chem. Educ. 2013, 90, 1018.

99. Tariq, M.; Carvalho, P. J.; Coutinho, J. A. P.; Marrucho, I. M.; Lopes, J. N. C.; Rebelo, L. P. N.; Fluid Phase Equilib. 2011, 301, 22. 
100. Byrne, N.; Angell, C. A.; Chem. Commun. 2009, 1046.

101. Greaves, T. L.; Weerawardena, A.; Fong, C.; Krodkiewska, I.; Drummond, C. J.; J. Phys. Chem. B 2006, 110, 22479.

102. Jha, I.; Attri, P.; Venkatesu, P.; Phys. Chem. Chem. Phys. 2014, 16, 5514.

103. Rambaran, R. N.; Serpell, L. C.; Prion 2008, 2, 112.

104. Piotrowska, U.; Sobczak, M.; Oledzka, E.; Combes, C.; J. Appl. Polym. Sci. 2016, 133, 43728.

105. Wiest, J.; Saedtler, M.; Balk, A.; Merget, B.; Widmer, T.; Bruhn, H.; Raccuglia, M.; Walid, E.; Picard, F.; Stopper, H.; Dekant, W.; Lühmann, T.; Sotriffer, C.; Galli, B.; Holzgrabe, U.; Meinel, L.; J. Controlled Release 2017, 268, 314.

106. Monti, D.; Egiziano, E.; Burgalassi, S.; Chetoni, P.; Chiappe, C.; Int. J. Pharm. 2017, 516, 45.

107. Stolte, S.; Matzke, M.; Arning, J.; Böschen, A.; Pitner, W.-R.; Welz-Biermann, U.; Jastorff, B.; Ranke, J.; Green Chem. 2007, 9, 1170.

108. Lovejoy, K. S.; Corley, C. A.; Cope, E. K.; Valentine, M. C.; Leid, J. G.; Purdy, G. M.; Wilkes, J. S.; Koppisch, A. T.; Del Sesto, R. E.; Cryst. Growth Des. 2012, 12, 5357.

109. Lovejoy, K. S.; Davis, L. E.; McClellan, L. M.; Lillo, A. M.; Welsh, J. D.; Schmidt, E. N.; Sanders, C. K.; Lou, A. J.; Fox, D. T.; Koppisch, A. T.; Del Sesto, R. E.; J. Appl. Phycol. 2013, 25, 973.

110. Ketonis, C.; Barr, S.; Adams, C. S.; Shapiro, I. M.; Parvizil, J.; Hickok, N. J.; Antimicrob. Agents Chemother. 2011, 55, 487.

111. Hall-Stoodley, L.; Costerton, J. W.; Stoodley, P.; Nat. Rev. Microbiol. 2004, 2, 95.

112. Chantasart, D.; Li, S. K.; Pharmaceutics 2012, 4, 71.

113. Wu, H.; Moser, C.; Wang, H.; Høiby, N.; Song, Z.; Int. J. Oral Sci. 2015, 7, 1.

114. Skinner, N.; Nature 2014, DOI: 10.1038/nature.2014.15763.

115. Miwa, Y.; Hamamoto, H.; Ishida, T.; Eur. J. Pharm. Biopharm. 2016, 102, 92.

116. Bseiso, A.; Nasr, M.; Sammour, O.; El Gawad, A.; Indian J. Dermatol. Venereol. Leprol. 2015, 81, 457.

117. Prausnitz, M.; AIChE J. 2015, 61, 2732.

118. Siopa, F.; Figueiredo, T.; Frade, R.; Neto, I.; Meirinhos, A.; Reis, C.; Sobral, R.; Afonso, C.; Rijo, P.; ChemistrySelect 2016, 1, 5909.

119. Carquigny, S.; Lakard, B.; Lakard, S.; Moutarlier, V.; Hihn, J.; Viau, L.; Electrochim. Acta 2016, 211, 950.

120. Waterman, K. C.; Adami, R. C.; Alsante, K. M.; Antipas, A. S.; Arenson, D. R.; Carrier, R.; Hong, J.; Landis, M. S.; Lombardo, F.; Shah, J. C.; Shalaev, E.; Smith, S. W.; Wang, H.; Pharm. Dev. Technol. 2002, 7, 113.

121. Yamaguchi, T.; Kawai, K.; Yamanaka, K.; Tatsumi, N.; US pat. 86233872014.

122. Kubota, K.; Shibata, A.; Yamaguchi, T.; Eur. J. Pharm. Sci. 2016, 86, 75.

123. Alves, M.; Vieira, N.; Rebelo, L.; Araújo, J.; Pereiro, A.; Archer, M.; Int. J. Pharm. 2017, 526, 309.
124. Noritomi, H. In Ionic Liquids - New Aspects for the Future; Kadokawa, J., ed.; InTech: Rijeka, Croatia, 2013, ch. 22.

125. Chevrot, G.; Fileti, E.; Chaban, V.; J. Mol. Model. 2016, 22, 258.

126. Klibanov, A. M.; Adv. Appl. Microbiol. 1983, $29,1$.

127. Noritomi, H.; Kai, R.; Iwai, D.; Tanaka, H.; Kamiya, R.; Tanaka, M.; Muneki, K.; Kato, S.; J. Biomed. Sci. Eng. 2011, 4, 692.

128. Ikegaya, K.; J. Biochem. 2005, 137, 349.

129. Illanes, A.; Electron. J. Biotechnol. 1999, $2,1$.

130. Kaushik, J. K.; Bhat, R.; J. Phys. Chem. B 1998, 102, 7058.

131. Cioci, F.; Lavecchia, R.; Chem. Biochem. Eng. Q. 1998, 12, 191.

132. Santoro, M. M.; Liu, Y.; Khan, S. M.; Hou, L. X.; Bolen, D. W.; Biochemistry 1992, 31, 5278.

133. Arakawa, T.; Bhat, R.; Timasheff, S. N.; Biochemistry 1990 , 29, 1924.

134. Yancey, P. H.; Clark, M. E.; Hand, S. C.; Bowlus, R. D.; Somero, G. N.; Science 1982, 217, 1214.

135. Lee, J. C.; Timasheff, S. N.; J. Biol. Chem. 1981, 256, 7193.

136. Back, J. F.; Oakenfull, D.; Smith, M. B.; Biochemistry 1979, $18,5191$.

137. Mahler, H.-C.; Friess, W.; Grauschopf, U.; Kiese, S.; J. Pharm. Sci. 2009, 98, 2909.

138. Vrikkis, R. M.; Fraser, K. J.; Fujita, K.; MacFarlane, D. R.; Elliott, G. D.; J. Biomech. Eng. 2009, 131, 074514-1.

139. Rawat, K.; Bohidar, H. B.; Int. J. Biol. Macromol. 2015, 73, 23.

140. Sivapragasam, M.; Moniruzzaman, M.; Goto, M.; Biotechnol. J. 2016, 11, 1000.

141. Earle, M. J.; Seddon, K. R.; Pure Appl. Chem. 2000, 72, 1391. 142. Kumar, A.; Venkatesu, P.; Biophys. Rev. 2018, 10, 841.

143. Fujita, K.; MacFarlane, D. R.; Forsyth, M.; Yoshizawa-Fujita, M.; Murata, K.; Nakamura, N.; Ohno, H.; Biomacromolecules 2007, 8, 2080.

144. de Diego, T.; Lozano, P.; Gmouh, S.; Vaultier, M.; Iborra, J. L.; Biomacromolecules 2005, 6, 1457.

145. Baker, S. N.; McCleskey, T. M.; Pandey, S.; Baker, G. A.; Chem. Commun. 2004, 0, 940.

146. Byrne, N.; Wang, L.-M.; Belieres, J.-P.; Angell, C. A.; Chem. Commun. 2007, 0, 2714.

147. Lange, C.; Patil, G.; Rudolph, R.; Protein Sci. 2005, 14, 2693.

148. Heller, W. T.; O'Neill, H. M.; Zhang, Q.; Baker, G. A.; J. Phys. Chem. B 2010, 114, 13866.

149. Zaks, A.; Klibanov, A. M.; J. Biol. Chem. 1988, 263, 3194.

150. Klähn, M.; Lim, G. S.; Seduraman, A.; Wu, P.; Phys. Chem. Chem. Phys. 2011, 13, 1649.

151. Pandey, S.; Fletcher, K. A.; Baker, S. N.; Baker, G. A.; Analyst 2004, 129, 569.

152. Patel, R.; Kumari, M.; Khan, A. B.; Appl. Biochem. Biotechnol. 2014, 172, 3701.

153. Bose, S.; Armstrong, D. W.; Petrich, J. W.; J. Phys. Chem. B 2010, 114, 8221. 
154. Tamura, K.; Nakamura, N.; Ohno, H.; Biotechnol. Bioeng. 2012, 109, 729.

155. Galamba, N.; J. Phys. Chem. B 2012, 116, 5242.

156. Baker, G. A.; Heller, W. T.; Chem. Eng. J. 2009, 147, 6.

157. Tomé, L. I. N.; Jorge, M.; Gomes, J. R. B.; Coutinho, J. A. P.; J. Phys. Chem. B 2012, 116, 1831.

158. Weibels, S.; Syguda, A.; Herrmann, C.; Weingartner, H.; Phys. Chem. Chem. Phys. 2012, 14, 4635.

159. Agmon, N.; Acc. Chem. Res. 2012, 45, 63.

160. Sharp, K. A.; Vanderkool, J. M.; Acc. Chem. Res. 2010, 43, 231.

161. Raschke, T. M.; Levitt, M.; Proc. Natl. Acad. Sci. U. S. A. 2005, 102, 6777.

162. Vanzi, F.; Madan, B.; Sharp, K.; J. Am. Chem. Soc. 1998, 120, 10748.

163. Bellissent-Funel, M. C.; Hassanali, A.; Havenith, M.; Henchman, R.; Pohl, P.; Sterpone, F.; van der Spoel, D.; Xu, Y.; Garcia, A. E.; Chem. Rev. 2016, 116, 7673.

164. Ball, P.; Chem. Rev. 2008, 108, 74.

165. Chaplin, M.; Nat. Rev. Mol. Cell Biol. 2006, 7, 861.

166. Madan, B.; Sharp, K.; J. Phys. Chem. 1996, 100, 7713.

167. Madan, B.; Sharp, K.; J. Phys. Chem. B 1997, 101, 11237.

168. Dill, K. A.; Biochemistry 1990, 29, 7133.

169. Luscher, M.; Ruegg, M.; Biochim. Biophys. Acta 1978, 533, 428.

170. Chen, X.; Yang, T.; Kataoka, S.; Cremer, P. S.; J. Am. Chem. Soc. 2007, 129, 12272.

171. Zhang, Y.; Furyk, S.; Bergbreiter, D. E.; Cremer, P. S.; J. Am. Chem. Soc. 2005, 127, 14505.

172. Tadeo, X.; López-Mendez, B.; Castaño, D.; Trigueros, T.; Millet, O.; Biophys. J. 2009, 97, 2595.

173. Bizzarri, A. R.; Cannistraro, S.; J. Phys. Chem. B 2002, 106, 6617.

174. Baldwin, R. L.; Biophys. J. 1996, 71, 2056.

175. Canchi, D. R.; Garcia, A. E.; Annu. Rev. Phys. Chem. 2013, 64, 273.

176. Schellman, J. A.; Biophys. J. 2003, 85, 108.

177. Davis-Searles, P. R.; Saunders, A. J.; Erie, D. A.; Winzor, D. J.; Pielak, G. J.; Annu. Rev. Biophys. Biomol. Struct. 2001, 30, 271.

178. Fenimore, P. W.; Frauenfelder, H.; McMahon, B. H.; Parak, F. G.; Proc. Natl. Acad. Sci. U. S. A. 2002, 99, 16047.

179. Ansari, A.; Jones, C. M.; Henry, E. R.; Hofrichter, J.; Eaton, W. A.; Science 1992, 256, 1796.

180. Voss, J. M.; Marsh, B. M.; Zhoua, J.; Garand, E.; Phys. Chem. Chem. Phys. 2016, 18, 18905.

181. Collins, K. D.; Methods 2004, 34, 300.

182. Volkin, D. B.; Klibanov, A. M.; Protein Function: Practical Approach; IRL Press: Oxford, UK, 1989.
183. Dabirmanesh, B.; Khajeh, K.; Ranjbar, B.; Ghazi, F.; Heydari, A.; J. Mol. Liq. 2012, 170, 66.

184. Dang, D. T.; Ha, S. H.; Lee, S. M.; Chang, W. J.; Koo, Y. M.; J. Mol. Catal. B: Enzym. 2007, 45, 118.

185. Persson, M.; Bornscheuer, U. T.; J. Mol. Catal. B: Enzym. 2003, 22, 21.

186. Buchfink, R.; Tischer, A.; Patil, G.; Rudolph, R.; Lange, C.; J. Biotechnol. 2010, 150, 64.

187. Lozano, P.; de Diego, T.; Carrié, D.; Vaultier, M.; Iborra, J. L.; Biotechnol. Lett. 2001, 23, 1529.

188. Noritomi, H.; Minamisawa, K.; Kamiya, R.; Kato, S.; J. Biomed. Sci. Eng. 2011, 4, 94.

189. Park, J.; Lee, C. K.; Kwon, K.; Kim, H.; Int. J. Electrochem. Sci. 2013, 8, 4206.

190. Laszlo, J. A.; Compton, D. L.; J. Mol. Catal. B: Enzym. 2002, $18,109$.

191. Dang, L.-P.; Fang, W.-Z.; Li, Y.; Wang, Q.; Xiao, H.-Z.; Wang, Z.-Z.; Appl. Biochem. Biotechnol. 2013, 169, 290.

192. Tateishi-Karimata, H.; Sugimoto, N.; Nucleic Acids Res. 2014, 42, 8831 .

193. Micaêlo, N. M.; Soares, C. M.; J. Phys. Chem. B 2008, 112, 2566.

194. Karbalaei-Heidari, H. R.; Shahbazi, M.; Absalan, G.; Appl. Biochem. Biotechnol. 2013, 170, 573.

195. Wu, X.; Zhao, B.; Wu, P.; Zhang, H.; Cai, C.; J. Phys. Chem. B 2009, 113, 13365.

196. Zhang, J.; Lei, J.; Liu, Y.; Zhao, J.; Ju, H.; Biosens. Bioelectron. 2009, 24, 1858.

197. Moniruzzaman, M.; Kamiya, N.; Goto, M.; Langmuir 2009, $25,977$.

198. Zhao, H.; Jackson, L.; Song, Z.; Olubajo, O.; Tetrahedron: Asymmetry 2006, 17, 1549.

199. Ulbert, O.; Bélafi-Bakó, K.; Tonova, K.; Gubicza, L.; Biocatal. Biotransform. 2005, 23, 177.

200. Madeira Lau, R.; Sorgedrager, M. J.; Carrea, G.; van Rantwijk, F.; Secundo, F.; Sheldon, R. A.; Green Chem. 2004, 6, 483.

201. Larsen, A. S.; Holbrey, J. D.; Tham, F. S.; Reed, C. A.; J. Am. Chem. Soc. 2000, 122, 7264.

202. van Rantwijk, F.; Madeira Lau, R.; Sheldon, R. A.; Trends Biotechnol. 2003, 21, 131.

203. Potdar, M. K.; Kelso, G. F.; Schwarz, L.; Zhang, C.; Hearn, M. T. W.; Molecules 2015, 20, 16788.

204. Chen, W.-J.; Lou, W.-Y.; Yu, C.-Y.; Wu, H.; Zong, M.-H.; Smith, T. J.; J. Biotechnol. 2012, 162, 183.

Submitted: May 16, 2018

Published online: July 24, 2018 